\title{
Clinical and Bacteriological Profile of Community Acquired Pneumonia among Adult Patients
}

\author{
Aji Mathew Joseph ${ }^{1}$, Mohamed Izudheen Irshad K.² \\ ${ }^{1}$ Department of Pulmonology, Believers Church Medical College Hospital, Thiruvalla, Kerala, India. \\ ${ }^{2}$ Department of Pulmonology, KIMS Alshifa Hospital, Perinthalmanna, Kerala, India.
}

\section{ABSTRACT}

\section{BACKGROUND}

Community acquired pneumonia is an acute illness acquired in the community with symptoms suggestive of LRTI. Pneumonia is one of the leading causes of death and morbidity, both in developing and developed countries and is the commonest cause of hospitalization in adults and children. We wanted to assess the clinical and bacteriological presentation of CAP.

\section{METHODS}

This is a cross sectional study conducted among 50 patients. Both out patients and inpatients of the Department of Pulmonology were included in the study. Pretested and predesigned proforma is used to collect the data. Analysis was carried out in statistical software SPSS Ver. 19.0.

\section{RESULTS}

$76 \%$ of CAP patients are males of which $58 \%$ were elderly ( $>50$ yrs.). The study group consisted of 50 patients among whom 38 (76\%) were males and 12 (24\%) were females. Dyspnoea is significantly more common among elderly CAP patients and chest pain more common among in younger CAP patients. S. pneumoniae being more common pathogen in CAP accounting for $38 \%$.

\section{CONCLUSIONS}

In our study, CAP was found more commonly between $3^{\text {rd }}$ and $5^{\text {th }}$ decade of life with a male:female ratio of 3.1:1. Most common presenting symptoms were cough with expectoration and fever. Streptococcus pneumoniae was the commonest organism isolated followed by Pseudomonas aeruginosa and Staphylococcus aureus.

\section{KEY WORDS}

Community Acquired Pneumonia, Streptococci, Pseudomonas; Staphylococci, Klebsiella
Corresponding Author: Dr. Aji Mathew Joseph, Assistant Professor, Department of Pulmonology, BCMCH, Thiruvalla - 689103, Kerala, India. E-mail: ajizzz9@gmail.com

DOI: $10.14260 /$ jemds $/ 2019 / 721$

Financial or Other Competing Interests: None.

How to Cite This Article:

Joseph AM, Irshad MIK. Clinical and bacteriological profile of community acquired pneumonia among adult patients. J. Evolution Med. Dent. Sci. 2019;8(44): 3323-3325, DOI: $10.14260 /$ jemds $/ 2019 / 721$

Submission 30-07-2019, Peer Review 19-10-2019,

Acceptance 26-10-2019, Published 04-11-2019.

\section{(i) $(9$}




\section{BACKGROUND}

Pneumonia is defined as a syndrome caused by acute infection, usually bacterial, characterized by clinical and/or a radiographic sign of consolidation of a part or parts of one or both lungs. ${ }^{1}$ Pneumonia that develops outside the hospital is community acquired pneumonia (CAP). ${ }^{2}$ Pneumonia signifies a pulmonary inflammatory process. The most significant and striking feature of which is consolidation. ${ }^{3}$ Community acquired pneumonia is an acute illness acquired in the community with symptoms suggestive of LRTI together with presence of a chest radiograph of intra pulmonary shadowing. All these have led to the need for understanding of immunological status of the individual. With the beginning of antibiotic era, the mortality rate levelled off and remained fairly constant. This mortality rate is heavily weighted against elderly. This predilection of pneumonia for elderly is not new and led William Osler in 1898 to describe as 'friend of the aged'. The true incidence of pneumonia acquired in the community is unknown and undoubtedly many pneumonic episodes are which is likely to be new and has no clear alternative cause. ${ }^{3}$ Estimates of the incidence of CAP range from 4 to 5 million cases per annually, which is about $20 \%$ of these require hospitalization. But the problem is much greater in developing countries where the pneumonia is the most common cause of hospital attendance in adults. ${ }^{4}$ With the beginning of the antibiotic era, the mortality rate levelled off and remained fairly constant. This mortality rate is heavily weighted against elderly. This prediction of pneumonia for elderly is not new and led William Osler in 1898 to describe as "pneumonia is a special enemy of old age." The cause of CAP is often difficult to establish. Despite the progress made in the diagnosis of pneumonia, it takes a few days to identify the causative micro-organism in the blood or sputum samples and the aetiology of half of all patients with CAP remains uncertain. ${ }^{5}$ In recent years, both the epidemiology and treatment of pneumonia have undergone changes. Pneumonia is increasingly common among older patients and those with co-morbidity like COPD, DM, renal failure, congestive heart failure, CLD and other conditions. ${ }^{6}$ This study is to understand the mode of presentation, its clinical and bacteriological features for the early detection of disease, the causative agent and to study its complications.

We wanted to assess the various types of clinical presentation of CAP and determine the spectrum of organisms causing CAP.

\section{METHODS}

This is a cross sectional study conducted among patients above 18 years of age, who presented with features of CAP (fever with chills and rigors, cough with expectoration, chest pain and breathlessness) in the Department of Pulmonology, Navodaya Medical College Hospital and Research Centre, Raichur, between January 2014 to December 2014. Both outpatients and inpatients were included in the study. The subjects were selected by simple random sampling method.

All the patients were subjected to detailed clinical examination to make a provisional diagnosis of community acquired pneumonia (CAP). All relevant investigations including WBC count and differential count, sputum for Gram stain, fungal elements, AFB, and culture were done, chest Xray were done to determine the site of consolidation. Patients not consenting for the study, patients with aspiration pneumonia and patients with hospital acquired pneumonia were excluded from the study.

\section{Ethical Issues}

Permission was obtained from the institutional Ethical Committee. Informed written consent is taken from the patients fulfilling the eligibility criteria and been informed about the type of study and assurance is given for maintenance of confidentiality of the patient.

\section{Data Analysis}

Pretested and predesigned proforma is used to collect the data. Entry was carried in MS Excel sheet. Analysis carried out in statistical software version SPSS 19.0. Results are expressed in terms of percentage and statistical methods like chi square were used. $p$ value $<0.05$ is taken as significant.

\section{RESULTS}

\begin{tabular}{|c|c|c|c|c|}
\hline \multirow{2}{*}{ Age Group } & \multicolumn{3}{|c|}{ Male } & \multicolumn{2}{c|}{ Female } \\
\cline { 2 - 5 } & No. & $\mathbf{\%}$ & No. & \% \\
\hline $18-20$ & 0 & $0.00 \%$ & 1 & $8.33 \%$ \\
\hline $21-30$ & 3 & $7.89 \%$ & 2 & $16.66 \%$ \\
\hline $31-40$ & 5 & $13.15 \%$ & 2 & $16.66 \%$ \\
\hline $41-50$ & 6 & $15.78 \%$ & 2 & $16.66 \%$ \\
\hline $51-60$ & 18 & $47.36 \%$ & 4 & $25.00 \%$ \\
\hline $61-70$ & 5 & $13.15 \%$ & 1 & $8.34 \%$ \\
\hline $71-80$ & 1 & $3 \%$ & 0 & $0 \%$ \\
\hline Total & $\mathbf{3 8}$ & $\mathbf{7 6 \%}$ & $\mathbf{1 2}$ & $\mathbf{2 4 \%}$ \\
\hline \multicolumn{4}{|c|}{ Table 1. Age and Sex Distribution } \\
\hline
\end{tabular}

\begin{tabular}{|c|c|c|c|c|}
\hline & Present & $\mathbf{\%}$ & Absent & $\mathbf{\%}$ \\
\hline Fever & 47 & $94 \%$ & 3 & $6 \%$ \\
\hline Cough & 48 & $96 \%$ & 2 & $4 \%$ \\
\hline Expectoration & 43 & $86 \%$ & 7 & $14 \%$ \\
\hline Dyspnoea & 22 & $44 \%$ & 28 & $56 \%$ \\
\hline Chest pain & 30 & $60 \%$ & 20 & $40 \%$ \\
\hline \multicolumn{6}{|l|}{ Table 2. Presentation of Clinical Features in CAP Patients } \\
\hline
\end{tabular}

\begin{tabular}{|c|c|c|c|c|}
\hline & \multicolumn{2}{|c|}{ Present } & \multicolumn{2}{c|}{ Absent } \\
\hline & No. & $\mathbf{\%}$ & No. & \% \\
\hline Pallor & 3 & $6 \%$ & 47 & $94 \%$ \\
\hline Icterus & 0 & & 50 & $100 \%$ \\
\hline Clubbing & 9 & $18 \%$ & 41 & $82 \%$ \\
\hline Cyanosis & 0 & & 50 & $100 \%$ \\
\hline Lymphadenopathy & 0 & & 50 & $100 \%$ \\
\hline Oedema & 0 & & 50 & $100 \%$ \\
\hline \multicolumn{6}{|c|}{ Table 3. Presentation of GPE in CAP Patients } \\
\hline Clubbing was common among CAP patients (18\%). \\
\hline
\end{tabular}

\begin{tabular}{|c|c|c|}
\hline Organism & No. & \% \\
\hline Streptococcus (SP) & 18 & $36 \%$ \\
\hline Pseudomonas (PS) & 8 & $16 \%$ \\
\hline Staph aureus (SA) & 7 & $14 \%$ \\
\hline Klebsiella $(\mathrm{KL})$ & 4 & $8 \%$ \\
\hline E. coli (EC) & 3 & $6 \%$ \\
\hline H. influenza (HI) & 2 & $4 \%$ \\
\hline M. catarrhalis (MC) & 2 & $4 \%$ \\
\hline Acinetobacter (AB) & 1 & $2 \%$ \\
\hline Mixed & 2 & $4 \%$ \\
\hline Culture negative & 3 & $6 \%$ \\
\hline \multicolumn{2}{|c|}{ Table 4. Sputum Culture Report } \\
\hline \multicolumn{2}{|c}{}
\end{tabular}

$76 \%$ of CAP patients are males of which $58 \%$ were elderly ( $>50$ yrs.). The study group consisted of 50 patients among whom $38(76 \%)$ were males and $12(24 \%)$ were females. 
Among males 63\% were above 50 years. Dyspnoea is significantly more common among elderly CAP patients and chest pain is more common among in younger CAP patients. Cough was the commonest symptom (96\%) followed by fever (94\%), expectoration (86\%), chest pain (60\%) and dyspnoea in $44 \%$. Dyspnoea is significantly more common in elderly CAP patients $78.26 \%$ (odds ratio $20.7 \mathrm{p}<0.001$ highly significant) and chest pain is more common in younger CAP patients $66.66 \%$ (odds ratio $0.26 \mathrm{p}<0.05$ (significant), $\mathrm{x}^{2}$ =4.84). Sputum culture report showed Streptococcal pneumonia is more common constituted about 36\%, Pseudomonas 16\%, Staphylococci about 14\%, Klebsiella accounted about $8 \%$, E. coli $6 \%$ and mixed constituted $4 \%$ in this study.

\section{DISCUSSION}

In the present study, $58 \%$ are elderly of the total cases occurred between the age group of 19- 72 years. The incidence was higher in people aged over 50 years $(58 \%)$ than those who were below 50 years (42\%) In this study group patients below 18 years were not included, but majority of patients were middle aged and elderly. In the study of Shah BA \& others they found out that patient aged $>50$ years are more $(67 \%)$ as compared to less than 50 years (33\%) 8. Our study is on par with their study. In this study of 50 patients it was observed that majority of patients are males $(76 \%)$ in comparison to the female population (24\%). This could be attributed to the well-established fact that cigarette smoking and alcoholism, as well as underlying lung disease e.g. COPD predispose to pneumonia and are more common in a developing country like India. In this study group majority of male patients are exposed to one or more of the above-mentioned predisposing factors.

In this study, majority of patients had cough (96\%) followed by fever (94\%), expectoration $(86 \%)$, chest pain $(60 \%)$ and dyspnoea (44\%). In study by Shah BA and others aetiology and outcome of CAP, cough was the most frequent symptom (99\%), the other symptoms were fever (95\%), chest pain (75\%) and expectoration (65\%).

In the present study it is found that streptococcal pneumoniae being more common pathogen in CAP accounting for $36 \%$. Next common is Pseudomonas aeruginosa which accounts for $18 \%$ followed by Staphylococcus aureus 12\%, Klebsiella constituted about $8 \%$., E. coli $6 \%$ and $H$. influenza $4 \%$ This observation is similar to that of study done by Shrestha $\mathrm{R}$ et $\mathrm{al}^{8}$ and Vishak K. Acharya, Mahesha Padyana and others. ${ }^{9}$

\section{CONCLUSIONS}

In our study, CAP was found more commonly between $3^{\text {rd }}$ and $5^{\text {th }}$ decade of life with a male:female ratio of 3.1:1. Most common presenting symptoms were cough with expectoration and fever. Streptococcus pneumoniae was the commonest organism isolated followed by Pseudomonas aeruginosa and Staphylococcus aureus.

\section{REFERENCES}

[1] Crofton J, Douglas A, Seaton A. Crofton and Douglas's Respiratory diseases. $5^{\text {th }}$ edn. Oxford: Blackwell Science Publications 2000: p. 356-429.

[2] Fishman A. Fishman's pulmonary diseases and disorders. Vol. 1. $4^{\text {th }}$ edn. New York: McGraw-Hill Education 2002: p. 2097.

[3] Marrie TJ. Harrison's Principles of internal medicine. $16^{\text {th }}$ edn. 2005: p. 1528-38.

[4] MacFarlance J. Community acquired pneumonia. Br J Dis Chest 1987;81(2):116-27.

[5] Ishida $T$, Hashimoto $T$, Arita $M$, et al. Etiology of community acquired pneumonia in hospitalized patients: a 3-year prospective study in Japan. Chest 1998;114(6):1588-93.

[6] Marrie TJ, Durrant H, Yastes L. Community acquired pneumonia requiring hospitalization: a five year prospective study. Rev Infect Dis 1989;11(4):586-99.

[7] Shah BA, Singh G, Naik MA, et al. Bacteriological and clinical profile of community acquired pneumonia in hospitalized patients. Lung India 2010;27(2):54-7.

[8] Shrestha R, Paudel N, Barakoti B, et al. Etiology and clinical profile of inpatients with community acquired pneumonia in Manipal teaching hospital, Pokhara, Nepal. Nepal J Med Sci 2012;1(2):84-8.

[9] Acharya VK, Padyana M, Unnikrishnan B, et al. Microbial profile and drug sensitivity pattern among community acquired pneumonia patients in tertiary care centre in Mangalore, Coastal Karnataka, India. Journal of Clinical and Diagnostic Research 2014;8(6):MC04-MC06. 